\title{
Attempted Portraits: Photography, Obscurity, and the Articulation of the Past
}

\author{
CHRISTOPHER MORTON \\ Pitt Rivers Museum, University of Oxford \\ https://orcid.org/0000-0002-3358-591X
}

\begin{abstract}
The essay draws on two case studies from the photographic archive of British social anthropologist Edward Evan Evans-Pritchard (1902-73) on a fieldwork expedition to Kenya and South Sudan in 1936. The case studies reveal how connections can be made within an archive to articulate new narratives around often well-known photographs. The case studies explore the relationship between two different practices of looking: that involved in the act of photography, and that of looking at archival photographs as historical sources. Whilst the abundance of visual information in the archive reveals photography's endless potential for recodability, the essay argues that the photographic archive is also characterised by obscurity and limitation, and that the small dramas that are sometimes fleetingly glimpsed in the photographic hinterland will for the most part remain partial, unintelligible, and unarticulable by historians. Although there is a visual abundance in the photographic archive with which we might engage, what is shown to us is not abundantly clear. The essay argues that the important historical connections between the concepts of visibility and knowledge in a discipline such as anthropology often break down when the archive is recalcitrant, revealing its own limits as much as its bounty.
\end{abstract}

\section{Introduction}

This essay draws on two case studies from the photographic archive of British social anthropologist Edward Evan Evans-Pritchard (1902-73), emerging from two pieces of fieldwork he carried out in 1936 on a fieldwork expedition to Kenya and South Sudan. The two case studies both relate to what might be considered extended photographic events, with a number of images in the archive forming connections in space and time that come together to tell stories other than those perhaps originally intended, or as subsequently presented. It is the potential of the archive to become both a source for other lives of the singular image, and yet also an important limiting factor in revealing those lives that this essay engages with. The case studies explore the relationship between two different practices of looking: that involved in the act of photography itself, and the practice of looking at archival photographs as historical sources. I am particularly interested in the limitations in the relationship between these different practices because, for me, the question of limitations has been underexplored when compared to how the connections between the practices might 
reveal photographic excess or abundance. In her essay 'An Excess of Description' for instance, ${ }^{1}$ Deborah Poole argues that the inherently messy nature of the photographic encounter, and the inevitable visual excess of the resulting photograph, have plagued anthropological attempts to use the medium as a tool of racial description since it was first used - photography particularises, individualises and suggests a specific moment in time, when what was really wanted of the medium (at least in racial studies) was generality, objectivity and timelessness.

Elizabeth Edwards expanded our notion of photographic excess through the concept of abundance - what she describes as the 'plentifulness, plenitude and potential' of the photographic image. ${ }^{2}$ Rather than focusing solely on the ostensible object of study in the image, an abundance of visual information is available for consideration, in what is excessive to the main focus of the image, not originally intended for record, and in the marginalia of the image, or what I term its hinterland. It is here in the photographic margins where a plenitude of traces of lived experiences remain, and with which numerous social engagements now take place as they are brought into the public domain, exhibited and shared online. But with this abundance of information, comes partiality, uncertainty, glimpses, suggestions, questions and obscurity.

And it is obscurity - that which is not readily or only partially visible, describable, comprehendible and hence legible and understandable - that we need to acknowledge as an important social dimension of the visual abundance of the photograph, and of the archive as a whole. For while abundance does bring with it the possibility of recoding historical imagery in new ways, questions of visibility and obscurity remain almost as the flip side of abundance; a plenitude of unknowable or incomprehendible visual details that process their way across the archive. What we are dealing with in the archive, and its constituent elements, are traces of lived realities. However, these traces are only ever facets or entry points to a past that we cannot fully explore. One of the most memorable explorations of this idea is Georges Didi-Huberman's treatise on the few images known to have been taken by concentration camp inmates during the Second World War, in which he argues forcefully for a recognition of the embodied and lived experience that underpins the photographic moment; 'images that were snatched, at incredible risk, from a Real that they certainly didn't have time to explore' he writes, 'yet which managed in a few minutes to capture incompletely, fugitively, some aspects of that Real. ${ }^{3}$ This powerful argument that connects photography with its trace of the past has been augmented in recent years by ethnographic case studies that often reveal the appreciation by people of many cultures for direct and tangible traces of their family members, however problematic the context of their production. ${ }^{4}$ A different approach, derived from art historical models, has sought for many years to disconnect the photograph as an object from its natural referent,

1 D. Poole, 'An Excess of Description: Ethnography, Race, and Visual Technologies', Annual Review of Anthropology, 34, 2005: $159-79$.

E. Edwards, 'Anthropology and Photography: A Long History of Knowledge and Affect', Photographies, 8, 3, $2015,237$.

G. Didi-Huberman, Images in Spite of All: Four Photographs from Auschwitz (Chicago: University of Chicago Press, 2008), 60

M. Aird, 'Growing Up with Aborigines' in C. Pinney and N. Peterson (eds), Photography's Other Histories (Durham, NC, and

London: Duke University Press, 2003), 23-39. 
summed up in Berger and Mohr's memorable quip that 'photographs do not translate from appearance. They quote from them.'

It is often through the minor dramas played out in the photographic hinterland where, as signalled by Didi-Huberman, the concepts of abundance on the one hand, and historical obscurity and incompleteness on the other, come together to lead us into new historical narratives and understandings. This is particularly important when we consider what the act of looking at photographs and writing histories through them involves. As the historian and psychologist Eelco Runia has argued, 'our past - though irremediably gone - may feel more real than the world we inhabit'. For Runia, the discontinuities between the past and present are addressed through the concept of metonymy, a 'presence in absence' that acts as a metaphor for the interwoven nature of historical continuity and discontinuity. Photographs act as metonyms in Runia's sense, connecting lived experiences in the past to the experience of the past-in-the-present. Photographs as social objects speak to a past that is gone but which is also experienced and understood by those interacting with it today; they give tantalising access to a past, however obscure, 'that can be "visited" on the plane of the present.'

Obscurity is an important dimension of anthropological investigation, which, while it seeks to reveal social and cultural phenomena, is constantly dealing with the obscurity of such phenomena to the observer. The obscurity of socio-cultural phenomena to the anthropologist is also mirrored in the way the creation of knowledge by the anthropologist is obscured to their reader. The role of interlocuters, cultural experts, interpreters and others are rarely introduced to readers of ethnographic texts, but are more frequently pictured in the fieldwork photography archive. In Roger Sanjek's words, the obscuring of the role that such figures played in the creation of anthropological knowledge amounts to nothing less than 'intellectual colonialism in the study of "other cultures". ${ }^{8}$ But although the photographic archive has the potential 'to revise our textbooks - and write new ones' through an engagement with the abundance of information that photography affords, it is an abundance of fragments, traces, and gaps, as well as pitfalls of overinterpretation.

Problems of obscurity are a constant throughout much of Evans-Pritchard's work, whether in interpretations of Zande texts, or in difficulties accessing Nuer culture given their suspicion of him and the effects of colonial violence. 'When I entered a cattle camp it was not only as a stranger but as an enemy', he wrote, 'and they seldom tried to conceal their disgust at my presence, refusing to answer my questions and even turning away when I addressed them.9

\footnotetext{
J. Berger and J. Mohr, Another Way of Telling, 1982 (London: Granta, 1989), 128.

E. Runia, 'Presence', History and Theory, 45, 1, 2006, 6.

Runia 'Presence', 1.

R. Sanjek, 'Anthropology's Hidden Colonialism: Assistants and Their Ethnographers', Anthropology Today, 9, 2, 1993, 13.

E.E. Evans-Pritchard, The Nuer: A Description of the Modes of Livelihood and Political Institutions of a Nilotic People (Oxford:

Clarendon Press, 1940), 11.
} 
In the following case studies, I deal with two forms of such photographic and ethnographic obscurity, distance and darkness, both of which entwine anthropology as a form of disciplinary seeing and photography as a form of looking in particular ways. As Shawn Michelle Smith has argued, there is an important cultural distinction to be made between visibility and seeing, in which photography is heavily implicated. While photography has significantly expanded cultural ideas of what is visible, it also exposed its limits; sight was expanded and yet we also gained a strong sense of a world only partially perceptible to us. ${ }^{10}$

\section{Seeing (not seeing) I: Luoland 1936}

In 1936 Evans-Pritchard was awarded a grant by the Leverhulme Trust to continue his comparative studies of Nilotic groups, and this time he proposed to visit Kenya. However, as with his abortive attempt to study the Oromo in Ethiopia the year before, circumstances changed. His plan was to visit the Maasai or Turkana, but the Kenyan government advised against it given the difficulties the colonial administration was facing in those parts of the country. He decided that a brief visit to the Luo would be a good alternative, especially since there was so little social anthropological literature written about them.

The question of how closely the Luo fitted into Evans-Pritchard's developing theory of a wider Nilotic socio-political 'system', or whether he looked for and found corroborating evidence that it did fit, has been the subject of some debate. Illness kept his visit short, to around six weeks, and he was restricted to interviewing, in English, mainly Luo mission converts, while relying heavily on the Church Missionary Society archdeacon Walter Owen to guide him. It is therefore hardly surprising, and fully acknowledged by Evans-Pritchard himself, that his data were 'sketchy' and 'superficial. ${ }^{11}$

As an eloquent critic of the Kenyan administration, with genuine interests in African society and culture, Owen was an obvious choice as guide for any visiting academic. Shortly before Evans-Pritchard's visit, Owen had shown the archaeologist Louis Leakey around an archaeological site discovered when the Kisumu tennis club was adding another set of tennis courts. The combination of cultural interests and extensive Luo contacts made Owen stand out as someone who, to quote Evans-Pritchard, 'knew the Luo better than anyone has known them'. As he notes, his survey was made possible 'largely out of regard for the Archdeacon and Mrs Owen. ${ }^{12}$ Consequently, the photographs that he took on this visit to Luoland need to be understood both as an anthropologist's visual record, and as a record of local responses to an influential and respected local missionary, who was very often standing beside the photographer.

10 S. M. Smith, At the Edge of Sight: Photography and the Unseen (Durham and London: Duke University Press, 2013), 6.

11 E. E. Evans-Pritchard, 'Luo Tribes and Clans', Rhodes-Livingstone Journal, 7, 1949, 16.

12 Evans-Pritchard, 'Luo Tribes and Clans', 1. 


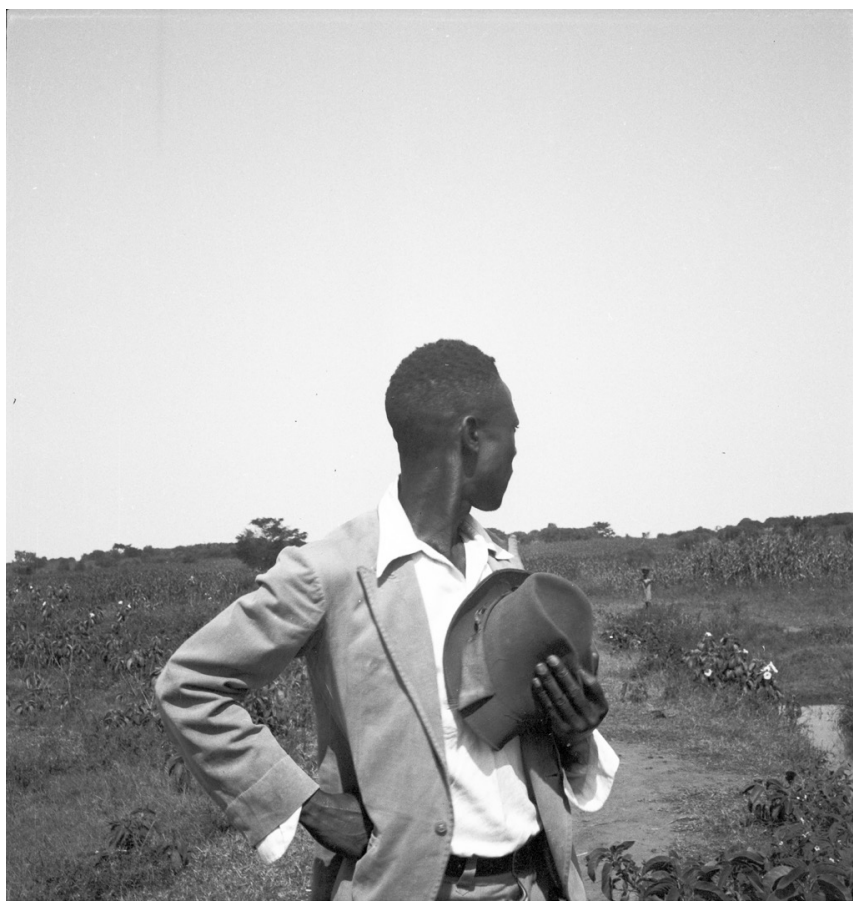

Figure 1: Attempted portrait of a Luo man near Gangu village, Siaya county, Nyanza, Kenya, 1936. Photograph by E. E. Evans-Pritchard. Courtesy Pitt Rivers Museum, University of Oxford (1998.349.245.1).

At some point during the visit, Owen took Evans-Pritchard to Gangu village, in Siaya county of Nyanza, where the photograph in this first case study was taken (Figure 1). Although the negative was uncaptioned by Evans-Pritchard, we know from other images that have the same background location that it was taken near this village. I first saw this image as an aberration, a failed attempt to take a portrait of a man who had taken his hat off so that his face would be more visible. Just at the crucial moment of exposure, the man seemingly turned around, his attention on some people further down the path, one of whom, a woman with a basket on her head, can be seen in the background. If the man had been facing the camera, as was presumably intended, it would be an unremarkable portrait, one of a number that Evans-Pritchard took of men attached to the Church Missionary Society mission at Maseno in western Kenya. But the longer we look at the image, which is striking, the more its metaphorical qualities come to the fore. These qualities are summed up in the caption - 'attempted portrait' - that I gave it for the cover of my book on Evans-Pritchard..$^{13}$ This is, after all, what anthropology tries to do: attempt to create a representation of a society or culture, which often resists such attempts. Although 

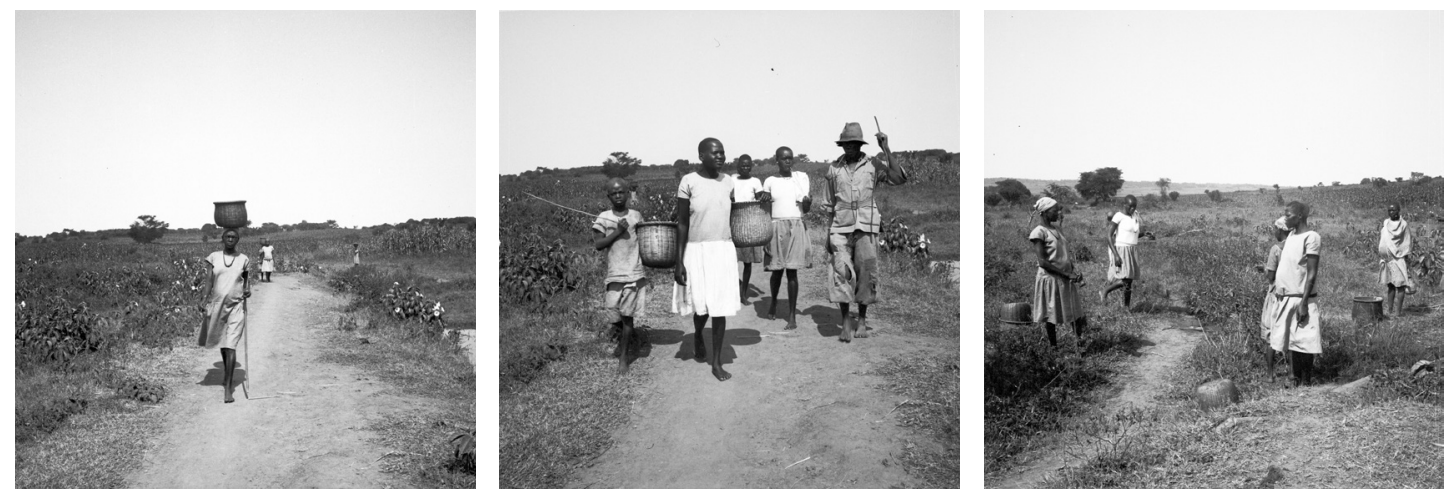

Figure 2: Woman carrying a basket on her head, near Gangu village, Siaya county, Nyanza, Kenya, 1936. Photograph by

E. E. Evans-Pritchard. Courtesy Pitt Rivers Museum,

University of Oxford (1998.349.243.1).

Figure 3: Group with baskets on a path near Gangu village,

Siaya county, Nyanza, Kenya, 1936. Photograph by E. E. Evans-

Pritchard. Courtesy Pitt Rivers Museum, University of Oxford

(1998.349.17.1).

Figure 4: Women with baskets on a path near Gangu village, Siaya county, Nyanza, Kenya, 1936. Photograph by E. E. EvansPritchard. Courtesy Pitt Rivers Museum, University of Oxford (1998.349.147.1).

the photograph is, on one level, a failed attempt to establish a portrait, it is arguably much more interesting as a result. It resists in its very nature what it is meant to be, that is, a full-face portrait, and yet it is also fully what it is at the same time. Other metaphors are at work here too, especially the submerged contributions of numerous local cultural experts, whose knowledge was sometimes particular to them and sometimes shared by their community. In Evans-Pritchard's work, these voices are often blended into the ethnography as 'the Nuer say' or 'the Azande say', but their faces and historical encounters with Evans-Pritchard only become clear when the photographic archive is revealed.

It is only when re-associating subsequently disconnected images in the archive that these submerged identities in the photographic hinterland emerge. ${ }^{14}$ In one of the related negatives (Figure 2) a woman walks towards the camera with a basket on her head, and to the right is the same woman standing in the distance who the man in 'attempted portrait' was turning back to look at. Standing in the same place,

14 This is often possible because Evans-Pritchard frequently noted the number of the negative pack on the back of his working prints. However, his prints subsequently became jumbled in his collection. This disorganisation was formalised when the collection entered the Pitt Rivers Museum, which preserved the order in which they arrived and numbered the collection accordingly. 


\section{(cc) BY-SA}
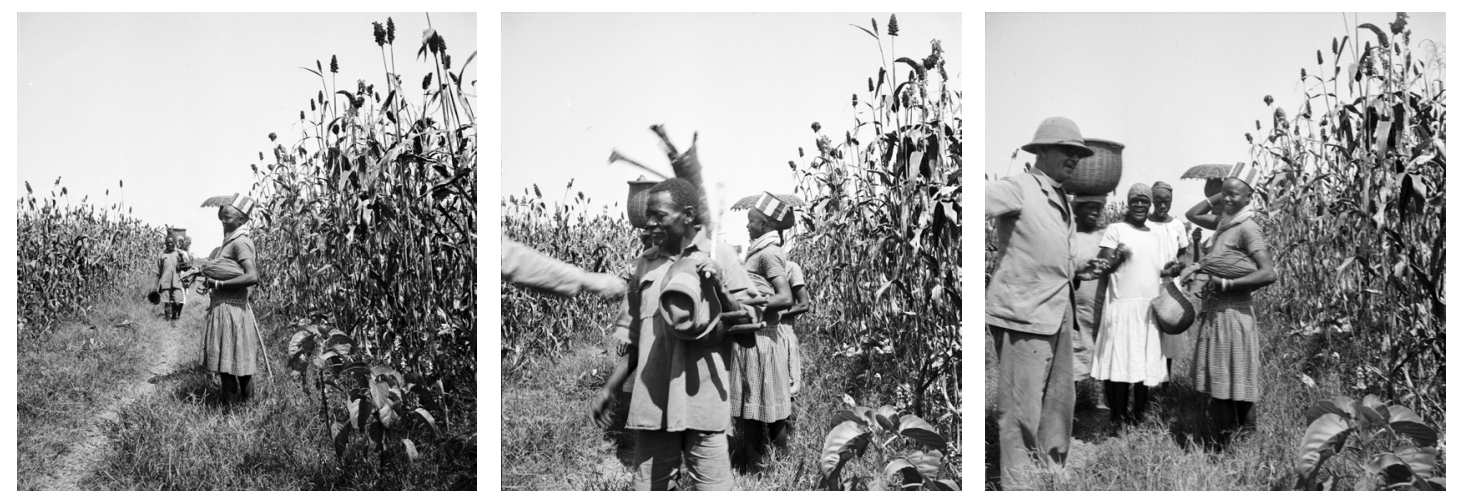

Figure 5: Woman wearing ligisa headdress on a path between fields of sorghum near Gangu village, Siaya county, Nyanza, Kenya, 1936. Photograph by E. E. Evans-Pritchard. Courtesy Pitt Rivers Museum, University of Oxford (1998.349.230.1).

Figure 6: Group on a path between fields of sorghum near Gangu village, Siaya county, Nyanza, Kenya, 1936. Photograph by E. E. Evans-Pritchard. Courtesy Pitt Rivers Museum, University of Oxford (1998.349.239.1).

Figure 7: Archdeacon Walter Owen with a group on a path between fields of sorghum near Gangu village, Siaya county, Nyanza, Kenya, 1936. Photograph by E. E. EvansPritchard. Courtesy Pitt Rivers Museum, University of Oxford (1998.349.25.1).

Evans-Pritchard takes another image (Figure 3) as more women with baskets, a boy, and a man walk towards him. Elsewhere on this same path, some of these same women appear in another image (Figure 4), which has a different feel to it - two of the women are standing quite stiffly, just off the path. Their awkwardness suggests discomfort with being photographed, or possibly that they have been asked to pose. Perhaps walking further into the fields, Owen and Evans-Pritchard encounter two women on a path between fields of sorghum, as a man and others behind him walk towards them. Possibly intrigued by the woman's headdress (known in dhoLuo as ligisa, worn by married women), he takes a photograph of her (Figure 5). The man and the other women walking down the path having now reached them, an arm reaches into the frame towards the man as Evans-Pritchard takes another exposure (Figure 6). In another photograph taken at the same time we now see who the arm belonged to, Archdeacon Owen himself, with a lit cigarette in his left hand, and the other gesturing out of frame to the left (Figure 7). Perhaps the arm gestures were intended to encourage the man to move out of the view of the camera so that EvansPritchard could photograph the women? In any case, the women seemingly find the situation amusing. Owen spoke dhoLuo, and was well known and respected locally as a missionary who often took up Luo welfare issues, to the consternation of colonial officials. 'As far as I can gather,' wrote C. M. Dobbs, provincial commissioner of 


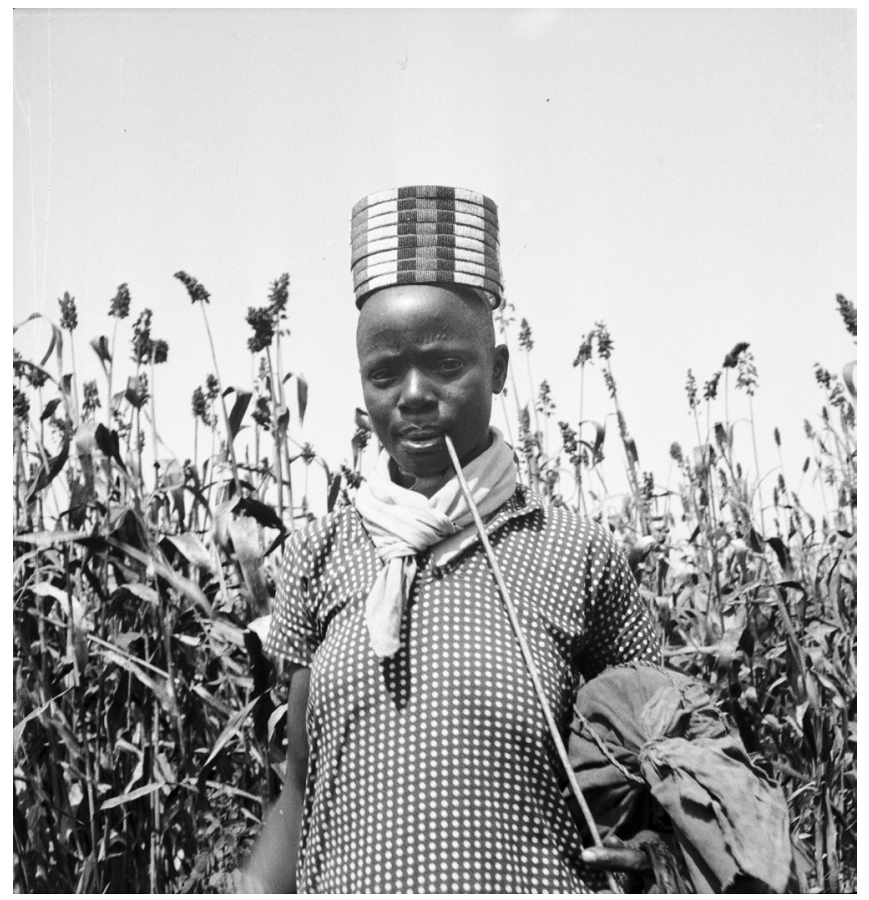

Figure 8: Portrait of a woman wearing ligisa headdress on a path between fields of sorghum near Gangu village, Siaya county, Nyanza, Kenya, 1936. Photograph by E. E. EvansPritchard. Courtesy Pitt Rivers Museum, University of Oxford (1998.349.81.1).

Nyanza in 1929, 'he does little or no mission work, but rushes round the country, trying to catch the wretched administrative officers out in some illegal act. ${ }^{15}$

One of the issues Owen took up with the administration was forced labour. Communal forced labour was an integral part of colonial rule in Nyanza, being essentially unpaid coerced labour for state purposes. ${ }^{16}$ Owen's moral outrage at the practice shocked audiences in England in 1938, when he told several congregations that 'certain features of British Administration in Kenya are but the modern expression of the desire to exploit for profit which gave rise to slavery. ${ }^{17}$ The apparently relaxed social interaction between Owen and the Luo on the path evident in this photograph offers an interesting insight into the local relationships of one of the most interesting late-colonial figures in Africa, whose historical role and influence is still keenly debated by African historians.

In the final image taken near Gangu village, Evans-Pritchard has managed to negotiate a full-face portrait of the woman wearing the ligisa headdress, pipe in mouth

15 Quoted in N. U. Murray, 'Archdeacon W. E. Owen: Missionary as Propagandist', International Journal of African Historical Studies, 15, 4, 1982, 659

16 O. Okia, 'In the Interests of Community: Archdeacon Walter Owen and the Issue of Communal Labour in Colonial Kenya, 1921-30', Journal of Imperial and Commonwealth History, 32, 1, 2004, 37.

17 Murray, 'Archdeacon W. E. Owen', 660. 
(Figure 8). The low angle of the portrait (as well as the negative format) shows that Evans-Pritchard was using the Rolleiflex camera that he bought in the early 1930s. To use this camera, the operator looks down into a ground-glass viewing screen to frame the image, rather than directly through a viewfinder. This involves a quite different type of social interaction than the standard viewfinder requires; the woman looks directly into the camera where the anthropologist engages with her as an image on glass, rather than face to face, before taking the exposure.

Yet throughout this series of images, the individual who really stands out is the one person who appears to be doing everything possible to avoid the missionary and the anthropologist - that is, the woman keeping her distance in 'attempted portrait', the woman that the man might be turning back to look at. In the series of images taken during the encounter on the path between sorghum fields, this woman stays out of view, hiding behind the woman wearing the ligisa headdress. And when the rest of the group are photographed walking towards the camera down the path through the fields (Figures 2 and 3), she remains in the far distance, with her basket and its woven basketry cover on her head, leaning on a long stick. Perhaps people are calling to her in the 'attempted portrait'. Perhaps the woman's suspicion of the European visitors, leading her to keep her distance, is known to the man who was to be the subject of the ethnographer's photograph, and he turns to look at her. We cannot be sure, but her presence - and yet non-presence - in most of the Gangu images is notable. Taken together, are these images evidence that the woman was reluctant to draw near the Europeans or to be photographed by them? We cannot really know the answer to this; it is one tantalising reading of this series of images.

Nonetheless the immediate context of the 'attempted portrait' can now be seen in a new light, not just as the attempted portrait of a man, but, in his turning away from the camera towards this woman, she becomes the central subject, and he the supporting character, mirroring her possible refusal to be photographed by turning away his own face. The question of Evans-Pritchard's photographic intentionality in relation to this set of photographs is not straightforward; few captions exist, so we are left to infer his intention from the subject matter, framing, and relationships between images. The similarities between some of the images is suggestive of opportunist snap-shot photography - the taking of further images of a subject if opportunities for a better view arise - the woman wearing the ligisa headdress, and the women carrying baskets, for example. As Edwards has argued, 'inscription outlives intention by the very nature of the photograph, and thus we have the beginning of a refiguration. ${ }^{18}$ The refiguration of the 'attempted portrait' photograph is a story I have told of wariness of the colonial encounter. This is one way of engaging with both the abundance and obscurity that play out in the hinterland of the photographic archive.

The photograph's abundance certainly transcends Evans-Pritchard's intention, whatever that may have been, in setting up the original exposure, enabling alternative readings and tantalising narratives about its social contexts to emerge. 'Attempted 
portrait' reflects the fugitive nature of anthropology's subject, the representation of social phenomena from one cultural context to another. Yet it could also represent a narrative of local resistance to the anthropological lens, the distant figures who chose not to approach, to remain out of sight of colonial scrutiny and its technologies of visual appropriation. Distance and proximity then become dimensions of social, historical and photographic obscurity; figures that sometimes do not articulate because they do not wish to do so.

\section{Seeing (not seeing) II: Nuerland 1936}

The focus of my second case study is a series of photographs taken by Evans-Pritchard in the village of Nyueny, in the Leek Nuer area of western Nuerland in South Sudan in October or November 1936. The images are dark, but clearly visible in one of them is a man thrusting a spear into the heart of a dark-coloured sacrificial ox in front of him (Figure 9). Silhouetted against a cloudy skyline, a number of other figures are witnessing the scene.

At the invitation of the Sudan government, Evans-Pritchard began fieldwork among the Nuer in 1930 and 1931, visiting again in 1935 and 1936. He later published several influential books, including The Nuer (1940), Kinship and Marriage Among the Nuer (1951) and Nuer Religion (1956). In the later fieldwork trips, five weeks in 1935 and seven weeks in 1936, he took over four hundred photographs on each visit roughly 10 per day on average. During his more extensive fieldwork trip in 1930 and 1931, when he spent eight-and-a-half months in Nuerland, he took on average about one photograph per day. His relative photographic inactivity during this first trip was related to the political situation in Nuerland at the time. The colonial administration's punitive strikes against the Nuer, in which livestock were a particular target, had created such mistrust that Evans-Pritchard 'abstained from photographing a single cow. ${ }^{19}$ The dramatic increase in his photographic activity in the two later periods of fieldwork was linked to several factors, including a slightly changed political context. Yet more important was his decision to visit the home villages of two former Nuer assistants he had employed during his first trip. In 1935, he went to Mancom at the mouth of the Nyanding River where his former assistant Tiop's family lived, and in 1936 he visited Nyueny, the home village of a youth called Nhial, 'as a friend of the family.20 The familiarity created by being introduced to these two communities in this way is clear. The photographs taken in 1935 and 1936 reveal an informality and level of access that was impossible in the earlier fieldwork. He even stated that to gain the acceptance of his Nuer hosts, he eventually acquired his own herd of cattle, which gave him a social existence and became a discussion point and opportunity to photograph the cattle camp.

The photograph (Figure 9) was probably taken shortly after sunset, hence the low light level. A group of people had come to make sacrifice at the homestead of a girl

19 E. E. Evans-Pritchard, 'The Economic Life of the Nuer: Cattle (Part 1)', Sudan Notes and Records, 20, 3, 1937, 242.

20 E. E. Evans-Pritchard, Nuer Religion (Oxford: Clarendon Press, 1956), 35. 


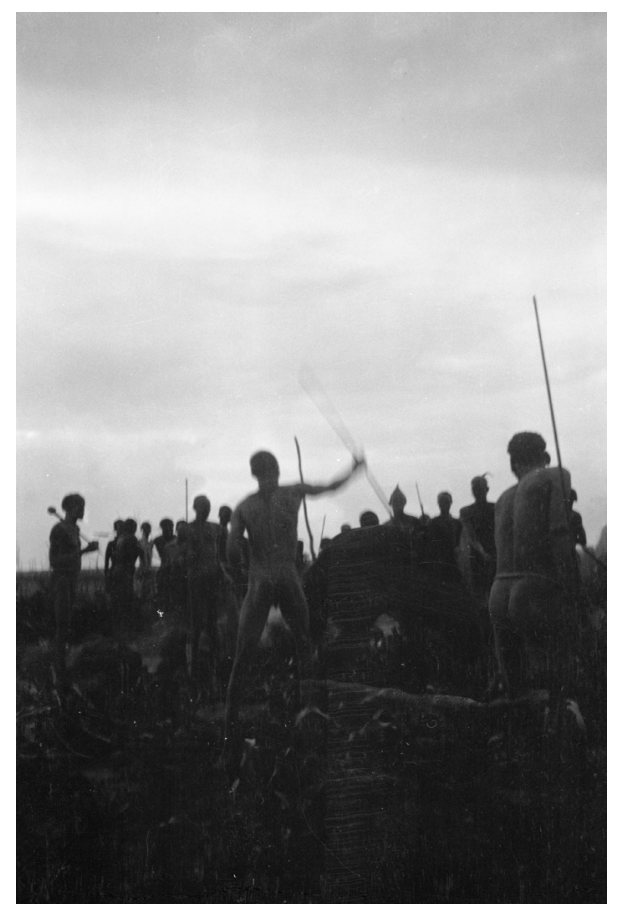

Figure 9: Man spearing a black ox in sacrifice for the spirit of a girl called Nyakewa killed by lightning. Nyueny village, Unity State, South Sudan, 1936. Photograph by E. E. EvansPritchard. Courtesy Pitt Rivers Museum, University of Oxford (1998.355.172.1).

called Nyakewa, who had been killed by lightning. According to Evans-Pritchard's account of Nuer practice in the 1930s, the Nuer believed that someone killed in this way became a col wic, a sacred spirit who has been taken directly by God. They would not be buried in the normal way, but covered over with the remains of their house (or grass and thornwood if killed in the bush). Sacrifices were then made as soon as possible in the homestead of the deceased, since the misfortune needed to be removed from the community. Evans-Pritchard describes the ritual activities following Nyakewa's death in some detail. In particular, one description seems to fit this photograph closely: 'Shortly before sunset a procession of about twenty men arrived...headed by the gwan buthni [ritual specialist] leading a black ox...The black ox was speared near the sacred stake and the sheep and goats were speared immediately afterwards. ${ }^{21}$ However, it is possible that the photograph was taken early the following morning, when a number of other animals were sacrificed by kin members. As Evans-Pritchard noted: 'At dawn the following morning the dead girl's senior 

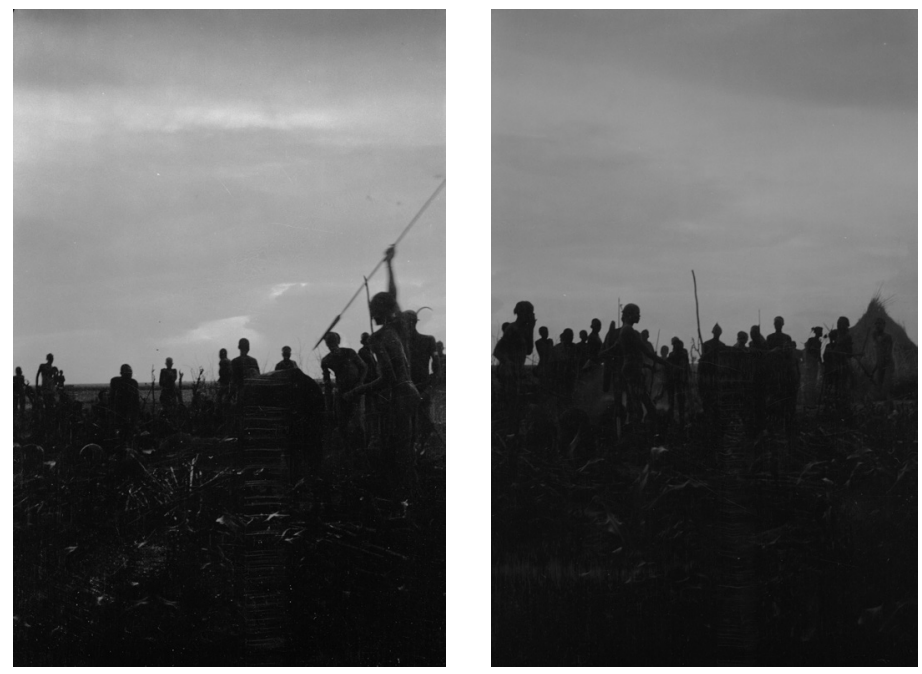

Figure 10: Man spearing a black ox in sacrifice for the spirit of a girl called Nyakewa killed by lightning. Nyueny village, Unity State, South Sudan, 1936. Photograph by E. E. EvansPritchard. Courtesy Pitt Rivers Museum, University of Oxford (1998.355.175.1).

Figure 11: Silhouettes at dusk of people witnessing the spearing of a black ox in sacrifice for the spirit of a girl called Nyakewa killed by lightning. Nyueny village, Unity State, South Sudan, 1936. Photograph by E. E. Evans-Pritchard. Courtesy Pitt Rivers Museum, University of Oxford (1998.355.172.1).

maternal uncle sacrificed a bull on behalf of the maternal kinsfolk... The uncle made a short oration before spearing it. ${ }^{22}$

Five more photographs in Evans-Pritchard's archive are closely connected to this one, using the same format and showing the same scene. One of them (Figure 10) shows the man holding his spear aloft, pointing it towards the ox - this could well show the uncle's 'short oration' as he addressed the col wic spirit. The oration seemingly lasted long enough for Evans-Pritchard to change position and to walk around the back of the man, perhaps to get a better view of the spearing. Another image (Figure 11) shows silhouettes of figures as they witnessed the sacrifice.

These photographs of the col wic ritual speak to the wider relationship between visibility, looking and knowledge in anthropology. According to Evans-Pritchard, the villagers of Nyueny told him that col wic meant 'black head' and that this name was used because Col, one of the sky gods who controlled lightning, was black-haired. Both the person killed by lightning, the col wic, and Col the god of lightning, seem intimately connected in Nuer thought. The association with darkness is also seen 
in the choice of sacrificial oxen, a thak ma col, which should be black: 'This ma col sacrificial victim, col the spirit of lightning, and the col wic make a harmony of darkness ( $c o l)$, the darkness of storm. ${ }^{23}$ The association between the col wic and darkness is then extended by the timing of the sacrifices connected with it, in the twilight of sunset and sunrise. Evans-Pritchard's account of Nuer conceptions of time is worth considering in this respect. In contrast to Western linear notions of time passing, the Nuer talked to Evans-Pritchard about time as a set of relationships between activities. In the annual cycle, this was based on seasonal changes and the activities that went with them, such as cattle camps and horticulture, and in the daily cycle of milking, for instance. Indicating when something might happen tended to be done with reference to such activities or to the position of the sun in the sky.

However, certain parts of the day were thicker with activity, and hence time, than others. Significantly, Evans-Pritchard noted that there were almost as many points of reference between 4 am and 6 am as there were for the rest of the day. 'This may be chiefly due', he wrote, 'to the striking contrasts caused by changes in relations of earth to sun during these two hours. ${ }^{24}$ While also noting Nuer terms for parts of the night, based on the movement of the stars, here again the vocabulary was richer around the transition between night and day than for the night time itself. Evans-Pritchard suggested that the richness of terms relating to the transitions of morning and evening is related to their role in directing activities that are commonly done at these times, such as starting journeys, tethering cattle etc., and that fewer terms exist for times when the heat of the day reduces activity.

The richness of social activity in these transitions between day and night raises interesting questions about the relationship between the anthropological method of participant-observation and visibility, as well as how variations in visibility can be traced in such things as ethnographic description, and especially the photographic record of fieldwork. As I have argued elsewhere (in relation to Evans-Pritchard's dramatic account of an Anuak séance which occurred at night, and so was not photographed), this raises the interesting issue that, historically, the relationship between anthropology and photography has been mostly a daytime affair, with a curfew of visualisation that ends with the setting of the sun..$^{25}$

Photographs such as those of the col wic sacrifice highlight the intensity of the relationship between visibility, seeing, and knowing in anthropology. In the gloom of sunrise or sunset, human eyes adjust well, yet cameras are less equipped to do so. The part-light of the day is an important reason why activities such as ritual take place when they do, in the transitional times between day and night, life and death. They do not take place in the dark, but as darkness is approaching or receding. Visibility during these rituals enables people to see, to witness the sacrifice, but the transitional time of day is important to its symbolic and social meaning. Evans-Pritchard's photographs of the col wic sacrifice bring us to the edge of visibility, a boundary 


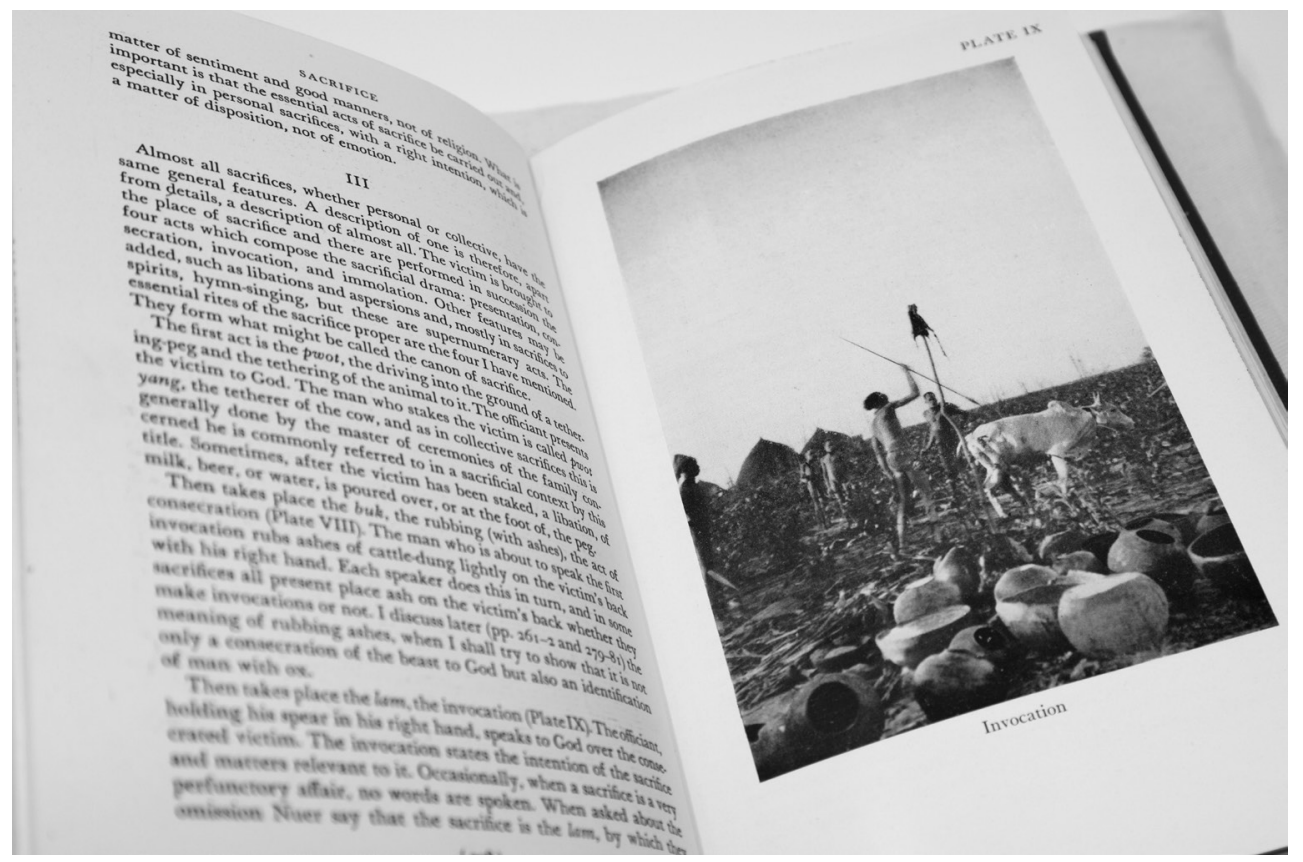

Figure 12: Plate IX (Invocation) from Nuer Religion by E. E. Evans-Pritchard (Oxford University Press, 1956), with the figure to right cropped. Photograph by the author.

where we perceive and interpret the visible world incompletely and inadequately. We struggle to see the sacrifice well because of the camera's poor sight, resulting in an underexposed image. When Evans-Pritchard came to illustrating sacrifice in his later volume, Nuer Religion, he used an image from the col wic ceremony, taken the following morning when the light was better (Figure 12). Yet the image itself, although more visible, does not allow us to see Nuer sacrifice better than the dark image, and indeed has been cropped heavily, presumably since the publisher saw the figure that was in the foreground of the original photograph as extraneous to the key element in the depiction - the man spearing the bull (Figure 13). Since the image was probably not taken during the main event of the previous evening, the image shows the sacrifice of a pale bull owned by Nyakewa's senior maternal uncle, not a black ox.

The function of such plates in anthropological monographs such as Nuer Religion is not so specific however. The aim is not to communicate something so complex that only a visual demonstration can suffice as part of the argument. It is rather to allow us to see the field for ourselves, to bring to perception the scenes described, and so to help our comprehension and the process of cultural translation. But then shouldn't the cropped figure of the person witnessing the sacrifice be just as important in the published version as the view of the sacrifice itself? Isn't a sense of participants' witnessing vital to our comprehension of the role of ritual in Nuer society? 


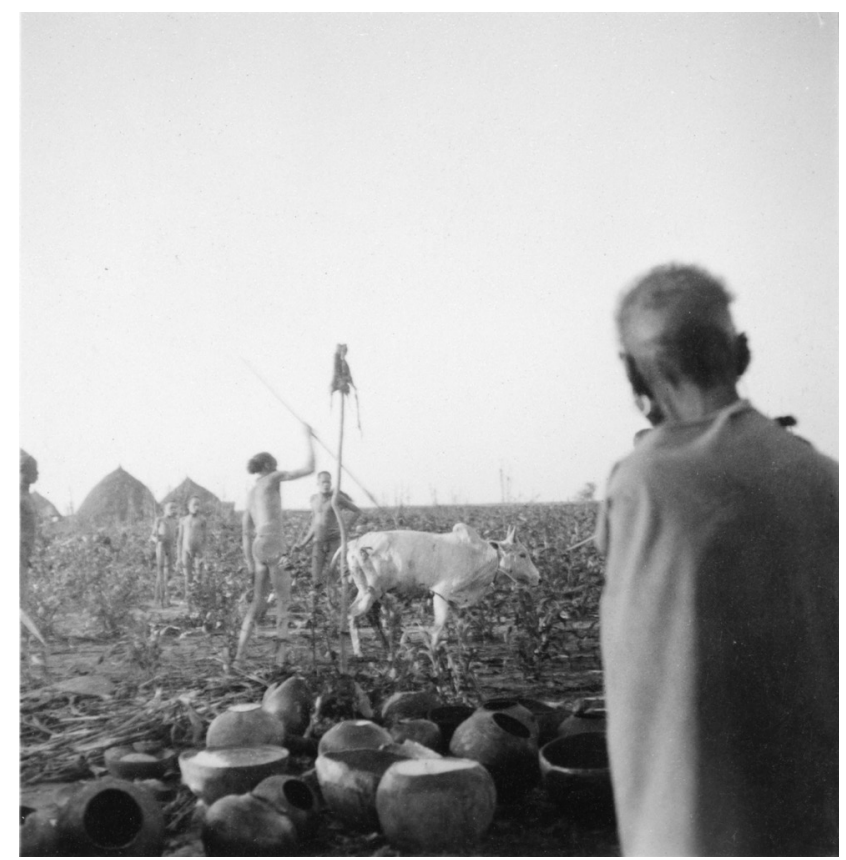

Figure 13: Nyakewa's senior maternal uncle spearing a pale bull in sacrifice for her col wic spirit, with figure watching (right, cropped in the printed version). Nyueny village, Unity State, South Sudan, 1936. Photograph by E. E. Evans-Pritchard. Courtesy Pitt Rivers Museum, University of Oxford (1998.355.247.2).

The col wic series of photographs and their published counterpart raise interesting questions about the limits of the relationship, not just between photography and anthropological knowledge, but of visibility, looking and understanding more broadly. How crucial is light to ethnographic description, whether photographic or otherwise? Of course, the issue of cultural visibility has implications for how South Sudan and its peoples have been represented in museums and ethnography over the years. Objects, sights, sounds, and experiences that were not accessible to anthropologists, whether as a result of darkness, as explored here, or because they were inappropriate for outsiders to see or know about, are hardly represented in written ethnographies or in museum displays. This historical distortion of South Sudanese culture has been compounded in more recent times by a lack of collecting activity that might address these representational issues in museums.

This is not to say however that anthropologists have not carried out fieldwork to bring Evans-Pritchard's 1930s Nuer ethnography up to date, and Sharon Hutchinson's work is notable in this respect. In her study of Leek Nuer responses to gun violence in the 1980s, for instance, she describes how people began to equate gunshot victims with lightning victims, believing that they too became col wic spirits: 'By thus equating the roar and flash of lightning with those of gunfire, Nuer survivors... were able 
to validate their losses and salvage something from their grief. ${ }^{26}$ This spiritual equation also gave courage to fighters since they knew that their relatives would ensure that they gained descendants through ghost-marriage after their death, a practice whereby a relative would marry someone in their name.

In the late 1980s, the practice of classifying bullet victims as col wic came to the attention of Nuer leaders such as Riek Machar. He immediately began a campaign against the practice, fearing it would cheapen this formerly rare category of spirits, and also affect the way fighters behaved in battle. Machar argued that there were two types of war and so two types of homicide - wars 'for the government' (koor kume) and local or 'homeland wars' (koor cieng). He pointed out that, since there was no possibility of claiming 'blood-wealth' in the form of cattle from a killer's family in the former, there was no need to purify soldiers from the tainted blood of those killed, or to memorialise the dead through sacrifice or ghost-marriage.

As Hutchinson argues, the ideological campaign against treating bullet victims as col wic spirits was intended to undermine any mediating structures that stood between Machar and the loyalty of his soldiers, including those of kinship, community and spirituality. The close link between these structures as represented in col wic was emphasized by both Evans-Pritchard, who argued that 'the conception of Spirit is refracted by the social structure, ${ }^{27}$ and by Hutchinson, who understood it as a cultural response to growing vulnerability to a new type of warfare, and how the collective used established religious practices to help them deal with the resulting sudden deaths. However, Hutchinson herself never witnessed a mortuary ceremony for a person killed by bullets, ${ }^{28}$ and so, like the dark images of the col wic ceremony, ethnographic knowledge is always limited and subject to issues of visibility, the ability to witness, and hence of understanding.

\section{Conclusion: Working with Obscurity}

As the anthropologist Anna Grimshaw noted, there is a curious paradox in the history of modern anthropology: the functionalist social anthropology promoted by Malinowski in the 1920s put vision and seeing for oneself at the heart of the discipline's method, and yet accorded little status or role to visual techniques or technologies. ${ }^{29}$ Nevertheless, what the archive suggests is a complex relationship between observation and participation in which photography has always played a crucial role. While for Grimshaw this method of participant-observation had little need for photography - since the data it provided related to surface appearance as opposed to social depth - in fact, photography became even more essential to the participatory as well as the ongoing observational method in the discipline, with anthropologists 
increasingly becoming participant-photographers, rather than detached and disinterested observers.

In my view, one of the main reasons for this is that photography became another form of collecting data from the perspective of the ethnographer as witness. To witness events is to participate, either directly or indirectly, and not just visually but using all the senses. The camera became part of the way in which participant-observation emerged as an ethnographic method; the camera operating as a notebook to record data that was fleeting, visually dense, and difficult to remember. Following Maurice Merleau-Ponty's insight that 'to see is to have at a distance, ${ }^{30}$ we can begin to understand the conceptual relationship between photography, seeing, and participating in anthropology as one in which looking and data collecting have always been closely linked. Tim Ingold makes a similar point when he argues that 'What we see is inseparable from how we see, and how we see is always a function of the practical activity in which we are engaged. ${ }^{31}$ Both photography and participantobservation have their own practices of looking and ways of seeing, which I argue have always been inextricably linked in the discipline of anthropology, and are certainly evident in Evans-Pritchard's archive.

To extend this, we need to consider practices of looking at photographs themselves, since how we see them, as much as what we see in them, is crucial to their potential as sources for writing history. This essay is an attempt to show one way in which archival looking can involve seeing relations between images, as well as the inherent ambiguity of what one sees. How intelligible can photographs really be when our vision of what they suggest is so imperfect? In the first case study, the relations between images taken during a visit to a village reveal a photographic hinterland, in which a narrative of social avoidance might be written, and yet will forever remain fugitive and elusive. In my second case study, I explored the relationship between photography, visibility, knowledge creation and dissemination. The historical connection between light and knowledge is nowhere more evident than in the use of photography in twentieth-century ethnographic fieldwork, where dusk imposed a curfew on the visual record of activities. Yet, while Evans-Pritchard's dim images of the col wic ritual are less legible, they contain within their shadows and silhouettes the very conditions that made the ritual efficacious - the transition from day to night and the spiritual liminality associated with it.

My intention in these two case studies from Evans-Pritchard's photographic archive has been to show how the concept of photographic abundance - the 'plenitude and potential' to be found in the photographic hinterland - is one that also deals with obscurity. The two examples are in many ways quite distinct, one dealing with the obscurity of distance and the other obscurity of light. And while these are both problems of visibility, they also represent problems with seeing and looking - with

30 M. Merleau-Ponty, 'Eye and mind' in J. Wild (ed.) The Primacy of Perception and Other Essays on Phenomenological Psychology, the Philosophy of Art, History and Politics (Evanston, IL: Northwestern University Press, 1964), 166.

31 T. Ingold, The Perception of the Environment: Essays in Livelihood, Dwelling and Skill (London and New York: Routledge, 2000), 260 (emphasis in original). 
how we are culturally attuned to read and understand images. Although there is a visual abundance with which we might engage, what is shown to us is not abundantly clear. I see an analogy here with how Evans-Pritchard grappled with issues of language and interpretation in both his recorded Zande texts, as well as his own anthropology. Take, for instance, his assertion that 'My interpretations are contained in the facts themselves, for I have described the facts in such a way that the interpretations emerge as part of the description. ${ }^{32}$ This blending (or if you will, obscuring) of data and interpretation in Evans-Pritchard's anthropology runs in parallel, I would argue, with the construction of the photographic archive, where image content, ordering, re-ordering, numbering, annotation, reproduction, commentary and other processes, all come together to create new meanings at different points in time. Both ethnographic and archival obscurity then have an interdependence, but it is one that emerges from the undoubtedly abundant potential of the photographic image as a starting point for new histories to be written. 